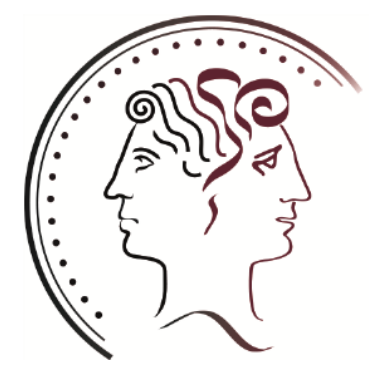

Working Papers of the Priority Programme 1859

Experience and Expectation.

Historical Foundations of Economic Behaviour

Edited by Alexander Nützenadel und Jochen Streb

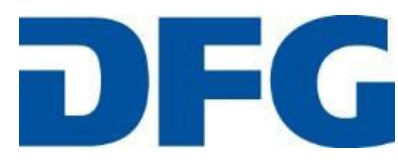

No 29 (2020, December)

Born, Benjamin / Dovern, Jonas / Enders, Zeno

Expectation dispersion, uncertainty,

and the reaction to news 
Arbeitspapiere des Schwerpunktprogramms 1859 der Deutschen Forschungsgemeinschaft „Erfahrung und Erwartung. Historische Grundlagen ökonomischen Handelns“ /

Working Papers of the German Research Foundation's Priority Programme 1859

"Experience and Expectation. Historical Foundations of Economic Behaviour"

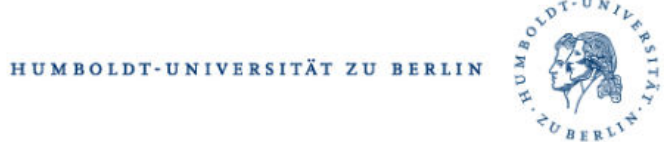

Published in co-operation with the documentation and publication service of the Humboldt University, Berlin (https://edoc.hu-berlin.de).

ISSN: 2510-053X

Redaktion: Alexander Nützenadel, Jochen Streb, Ingo Köhler

V.i.S.d.P.: Alexander Nützenadel, Jochen Streb

SPP 1859 "Erfahrung und Erwartung. Historische Grundlagen ökonomischen Handelns" Sitz der Geschäftsführung:

Humboldt-Universität

Friedrichstr. 191-193, 10117 Berlin

Tel: 0049-30-2093-70615, Fax: 0049-30-2093-70644

Web: https://www.experience-expectation.de

Koordinatoren: Alexander Nützenadel, Jochen Streb

Assistent der Koordinatoren: Ingo Köhler

Recommended citation:

Born, Benjamin / Dovern, Jonas / Enders, Zeno (2020): Expectation dispersion, uncertainty, and the reaction to news. Working Papers of the Priority Programme 1859 "Experience and Expectation. Historical Foundations of Economic Behaviour" No 29 (December), Berlin

(C) 2020 DFG-Schwerpunktprogramm 1859 „Erfahrung und Erwartung. Historische Grundlagen ökonomischen Handelns"

The opinions and conclusions set forth in the Working Papers of the Priority Programme 1859 Experience and Expectation. Historical Foundations of Economic Behaviour are those of the authors. Reprints and any other use for publication that goes beyond the usual quotations and references in academic research and teaching require the explicit approval of the editors and must state the authors and original source. 


\title{
Expectation dispersion, uncertainty, and the reaction to news*
}

\author{
Benjamin Born, Jonas Dovern, Zeno Enders
}

December 2020

\begin{abstract}
Releases of key macroeconomic indicators are closely watched by financial markets. We investigate the role of expectation dispersion and economic uncertainty for the stock-market reaction to indicator releases. We find that the strength of the financial market response to news decreases with the preceding dispersion in expectations about the indicator value. Uncertainty, in contrast, increases the response. We rationalize our findings in a model of imperfect information. In the model, dispersion results from a perceived weak link between macroeconomic indicators and fundamentals that reduces the informational content of indicators, while higher fundamental uncertainty makes this informational content more valuable.
\end{abstract}

Keywords: Expectation dispersion, uncertainty, macroeconomic news, stock market, event study, forecaster disagreement

JEL-Codes: E44, G12, G14

*Born: Frankfurt School of Finance \& Management, CEPR, and CESifo, b.born@fs.de, Dovern: FAU Erlangen-Nürnberg and CESifo, jonas.dovern@fau.de, Enders: Heidelberg University and CESifo, zeno.enders@uni-heidelberg.de. We thank Christian Conrad for helpful discussions. All remaining errors are ours. Jonas Dovern and Zeno Enders are grateful for financial support from the Deutsche Forschungsgemeinschaft (DFG) via its priority programme 1859 . 


\section{Introduction}

A cursory glance at the financial news media suggests that stock markets eagerly await releases of macroeconomic indicators, such as initial jobless claims or inflation, and that stock prices are highly sensitive to macroeconomic news, i.e., surprises in these indicators. This general perception is supported by a large academic literature showing that releases of macroeconomic information indeed move asset prices (e.g., Andersen et al., 2007; Beechey and Wright, 2009; Fleming and Remolona, 1999; Law et al., 2020, among many others). Importantly, this link between macroeconomic news and asset prices, i.e., the news effect, has been shown to vary across states of the economy, e.g., booms and recessions (Boyd et al., 2005; Gilbert, 2011; McQueen and Roley, 1993), and to depend on the informational content of individual indicators (Ehrmann and Sondermann, 2012; Gilbert et al., 2017).

This paper adds to the literature by showing that the news effect is influenced by two time-varying factors: expectation dispersion, i.e., forecaster disagreement, and aggregate economic uncertainty. Interestingly, while both factors affect the stock-market reaction to news, they do so in opposite directions. In our interpretation, these two factors represent the perceived information content of a specific indicator and the economic value of the contained information, respectively.

To show this formally, we first set up a theoretical model of imperfect information to derive hypotheses on how uncertainty and dispersion influence financial-market participants' reaction to macroeconomic news. In the model, the current fundamentals of the economy are unobserved, such that financial-market participants have to rely on occasional releases of observable indicators that are linked to the underlying fundamentals. This link, i.e., the informational content of these indicators, is time-varying. Agents receive private signals about the link, which are dispersed in case of a low informational content. In a nutshell, a large dispersion signals a higher noise content of a specific indicator, which also reduces its informational content regarding fundamentals. The market reaction to the subsequent indicator release is thus muted. That is, if financial analysts differ strongly in their belief about an upcoming indicator release, this release is unlikely to move markets much. 
Uncertainty about current fundamentals, on the other hand, relates to the volatility of shocks that move fundamentals. Information becomes more valuable in times of high uncertainty, such that markets react stronger to indicator releases for a given perceived link between these indicators and fundamentals. As a result, the model predicts that uncertainty about fundamentals and dispersed expectations of forecasters have opposite effects on the strength of the market reaction to news.

We then use high frequency data to analyze whether the degree of dispersion and uncertainty indeed affects how financial markets react to the releases of macroeconomic indicators. Our dataset includes 1,671 releases across six major macroeconomic indicators for the US economy. ${ }^{1}$ For each indicator release, we collect the prior individual forecasts of a panel of professional forecasters from Bloomberg, and compute both the dispersion of forecasts across the panel members, i.e., their disagreement, and the difference between the median forecast and the actual realization of the indicator, i.e., the news content of the release. Across indicators, there is notable heterogeneity in average dispersion. There is also considerable variation in dispersion over time. We measure uncertainty based on the real-uncertainty proxy of Ludvigson et al. (2021) in order to stay close to the uncertainty concept in the theoretical model, which is uncertainty about the fundamental. While average dispersion is correlated with the uncertainty proxy, the correlation coefficient is only about 0.5 .

To determine the stock market response to news releases, we conduct an event study that looks at the change in S\&P 500 futures prices between five minutes before the release of the respective indicator and five minutes afterwards. Specifically, we regress these returns on the news variable, forecast dispersion, the uncertainty measure, as well as - and most importantly for our investigation - interaction terms between news and dispersion and news and uncertainty, respectively.

\footnotetext{
${ }^{1}$ The indicators are, according to Law et al. (2020), the four with the strongest impact on stock marketschange in non-farm payrolls, initial jobless claims, the ISM manufacturing index, and the Conference Board consumer confidence index - plus GDP growth and the CPI inflation rate.
} 
Consistently for all indicators, we find that-holding uncertainty constant - an increase in expectation dispersion leads to weaker news effects on stock market returns, which is what our theoretical model predicts. These effects matter quantitatively: the effect of a onestandard-deviation surprise in, e.g., non-farm payrolls is halved if dispersion is one standard deviation above its mean. On the other hand, holding dispersion constant, macroeconomic news that materialize in more uncertain times generate a stronger stock market response than those hitting in tranquil times - again in line with the theoretical model. This also underpins that uncertainty and disagreement are not only different concepts that are imperfectly correlated (e.g., Giordani and Söderlind, 2003; Lahiri and Sheng, 2010; Zarnowitz and Lambros, 1987) but can actually have opposite effects.

Our findings are broadly robust to the choice of the uncertainty proxy and are not driven by the state of the business cycle. Interestingly, this does not hold true once we replace the baseline real uncertainty measure with monetary policy uncertainty (Husted et al., 2020). Here, we find that an increase in the latter counteracts the positive effect of favorable news on stock markets, in particular for those indicators that are deemed important for monetary policy decisions. This might be driven by, e.g., speculations about future interest rate hikes (see also Kurov and Stan, 2018). Given that the theoretical model makes predictions about the effects of uncertainty about real variables, this finding does not stand in contrast to our explanation regarding the effects of uncertainty and expectation dispersion.

The remainder of this paper is organized as follows: In Section 2, we set up our stylized model and show theoretically how uncertainty about fundamentals and dispersed expectations of forecasters have opposite effects on the reaction of markets to news. Section 3 then introduces the dataset and describes the empirical modeling approach. Section 4 contains the main empirical results from our event study and Section 5 checks their robustness. Finally, Section 6 concludes. 


\section{Model}

In this section, we set up a stylized model that will guide our thinking on how uncertainty and dispersion influence financial-market participants' reaction to macroeconomic news. As we will show, the model predicts that uncertainty about fundamentals and dispersed expectations of forecasters have opposite effects on the strength of the reaction of markets to news. In the model, the current fundamentals of the economy are unobserved, such that financial-market participants (traders from now on) have to rely on public indicators to form their expectations. The link of these indicators to the fundamentals is time-varying, e.g., because of developments that are unrelated to fundamentals but still have a bearing on a particular indicator release. Traders receive private signals about the link of the indicators to the fundamentals, or, equivalently, have a private and idiosyncratic interpretation of current circumstances. These private signals are dispersed in times of weak links between indicators and fundamentals, muting the market reaction to the subsequent indicator release. ${ }^{2}$ Uncertainty about current fundamentals, on the other hand, results from a higher volatility of shocks that move fundamentals. Information becomes more valuable in times of high uncertainty, such that markets react stronger to indicator releases for a given perceived link between these indicators and fundamentals.

\subsection{Setup}

There is a fundamental factor, think, e.g., of technology, that represents the potential of the economy and determines long-run profits of firms and, hence, current stock prices. Aggregate (log-) technology $x_{t}$ follows a random walk,

$$
x_{t}=x_{t-1}+\varepsilon_{t},
$$

\footnotetext{
${ }^{2}$ An example of such a weak link is the improvement of official labor market statistics running up to 2014, which was partly driven by discouraged workers leaving the labor force, and not only by an improving economic situation (Yellen, 2014). This was accompanied by an unusually large forecast dispersion for initial jobless claims in early 2014.
} 
with $\varepsilon_{t} \sim N\left(0, \sigma_{\varepsilon}^{2}\right)$. Agents do not observe technology directly. At various points in time, however, indicators that are linked to technology are released, from which agents can infer about current technology. Depending on the current combination of shocks in the economy, measurement error, and short-term developments, indicators may be more or less tightly linked to the underlying potential. They are, hence, only noisy signals about technology,

$$
i_{t}=\varepsilon_{t}+\nu_{t}(i)
$$

where the noisy component $\nu_{t}(i)$ is a draw from the distribution $N\left(\mu_{\nu, t}, \sigma_{\nu, t}^{2}\right)$, which exhibits a time-varying mean and volatility.

There is a unit mass of traders in the economy, who trade stocks based on private and public information. All information from period $t-1$ is released at the beginning of the current period. Put differently, $x_{t-1}$ summarizes all relevant information about technology up until shortly before the indicator release and is publicly known. Additionally, at the same time each trader $j \in\{0,1\}$ observes a private signal, $s_{t}(j)$, about the link between technology and a specific indicator. This signal is just another draw $\nu_{t}(j)$ from the distribution $N\left(\mu_{\nu, t}, \sigma_{\nu, t}^{2}\right)$ of the noisy component, such that

$$
s_{t}(j)=\nu_{t}(j)
$$

\subsection{Expectations before and after indicator release}

Given her private signal, trader $j$ forms an individual expectation about $\mu_{\nu, t}$. Because of her limited information, $E_{t, 1}^{j} \mu_{\nu, t}=\nu_{t}(j)$ and, hence, she predicts $i_{t}$ as $E_{t, 1}^{j} i_{t}=\nu_{t}(j)$. That is, expectations will be more dispersed if $\sigma_{\nu, t}^{2}$ is high and $s_{t}(j)$ is consequently more dispersed. Here, $E_{t, 1}^{j}$ represents the expectations of trader $j$ in the first stage of period $t$.

Figure 1 visualizes the intra-period timing of the model. The expectations are surveyed and published by a media firm in the middle of each period. The survey is published shortly 


\begin{tabular}{ccc}
\hline step 1 & step 2 & step 3 \\
$x_{t-1}$ known & expectations collected & indicator released \\
private signal & survey published & E $x_{t}$ updated \\
expectation of $i_{t}$ & noise distribution known &
\end{tabular}

Figure 1: Intra-period model timing

before the indicator is released. Since the expectations of a unit mass of traders are published, traders learn the exact values of $\mu_{\nu, t}$ and $\sigma_{\nu, t}^{2}$ from the survey publication and all forecasters now have homogeneous expectations. In particular, they estimate

$$
\begin{aligned}
& E_{t, 2} \mu_{\nu, t}=\int_{0}^{1} \nu_{t}(j)=\bar{\nu}_{t}=\mu_{\nu, t} \\
& E_{t, 2} \sigma_{\nu, t}^{2}=\int_{0}^{1}\left(\nu_{t}(j)-\bar{\nu}_{t}\right)^{2}=\sigma_{\nu, t}^{2} .
\end{aligned}
$$

Expectations regarding the indicator are therefore $E_{t, 2} i_{t}=\bar{\nu}_{t}$. Forecasters cannot, however, infer anything about technology in addition to $x_{t-1}$, which is public knowledge. Hence, no price change takes place after the release of the survey.

After the indicator is released in the third stage, new expectations regarding $x_{t}$ are formed. This formation follows a standard signal-extraction problem, where expectations are given by

$$
E_{t, 3} x_{t}=x_{t-1}+\rho_{i, t}\left(i_{t}-\bar{\nu}_{t}\right) \quad \text { with } \quad \rho_{i, t}=\frac{\sigma_{\varepsilon}^{2}}{\sigma_{\varepsilon}^{2}+\sigma_{\nu, t}^{2}} .
$$

Traders then trade proportionally to $E_{t, 3} x_{t}-E_{t, 2} x_{t}=E_{t, 3} x_{t}-x_{t-1}=\rho_{i, t}\left(i_{t}-\bar{\nu}_{t}\right)$. That is, if the indicator comes in as expected on average, prices do not change.

Hence, the model predicts that in times of high expectation dispersion (high $\sigma_{\nu, t}^{2}$ ), traders react less to new information than in times of low expectation dispersion. At the same time, in times of higher uncertainty (high $\sigma_{\varepsilon}^{2}$ ), the reaction to news is stronger. 


\section{$3 \quad$ Data and empirical model}

In this section, we first introduce the dataset and collect a number of stylized facts. We then set up and discuss the empirical model.

\subsection{Dataset}

To keep the analysis tractable, we focus on six major macroeconomic indicators. The first four are those that Law et al. (2020) found to induce the largest and most significant financial market movements: the change in non-farm payrolls (abbreviated as CNP), initial jobless claims (IJC), the ISM manufacturing index (ISM), and the Conference Board consumer confidence index (CCI). In addition, we consider GDP growth (GDP) and the inflation rate based on the consumer price index (CPI). These indicators vary in release frequency between weekly (IJC) and quarterly (GDP) and are released at 8:30 am, except for ISM and CCI, which are released at 10:00 am. Individual forecasts by professional forecasters covering these indicators come from Bloomberg. Forecasters can submit or update their predictions up to the night before the official indicator release, so these forecasts are likely to contain all available information at the time of the indicator release. To obtain reliable estimates of dispersion, we consider only data releases for which ten or more corresponding forecasts are available. While the earliest indicator release that fulfills this criterion takes place in August 1997, there are only eight of those releases before 1999. Our sample ends in March 2015. Overall, the number of data releases covered across time and indicators is 1,671, with an average number of panelists of $51.4 .^{3}$

\footnotetext{
${ }^{3}$ Note that our dataset is unbalanced as the frequency at which indicators are released and the start dates for indicator availability vary. See Table A.1 in the appendix for details.
} 
Given the individual forecast of forecaster $j$ for an indicator $i$ at time $t, \hat{y}_{j, t}^{i}$, we define dispersion as the cross-sectional standard deviation of forecasts:

$$
D_{t}^{i}=\frac{1}{N_{t}^{i}} \sum_{j=1}^{N_{t}^{i}}\left(\hat{y}_{j, t}^{i}-\frac{1}{N_{t}^{i}} \sum_{j=1}^{N_{t}^{i}} \hat{y}_{j, t}^{i}\right)^{2}
$$

where $N_{t}^{i}$ is the number of forecasts submitted for indicator $i$ at time $t$.

In addition, we compute a (normalized) measure of macroeconomic news, News $s_{t}^{i}$, by subtracting the median forecast from the published indicator value, $y_{t}^{i}$, and dividing by the standard deviation (across time) of this difference.

As measuring uncertainty directly is inherently difficult, we have to rely on proxies. For our baseline results, we use the real-uncertainty proxy of Ludvigson et al. (2021) to stay close to the uncertainty concept in the model of Section 2, which is uncertainty about the fundamental. Briefly speaking, the Ludvigson et al. (2021)-real-uncertainty measure is the common factor of the uncertainty connected to the individual variables covering the real economy. ${ }^{4}$

For the stock market data, we use tick-by-tick trades of S\&P 500 futures provided by TickData. We need to use futures data as most of the indicator releases are outside the trading hours of the New York Stock Exchange.

To get a first sense of the forecast dispersion in our sample, Panel (a) of Figure 2 displays the average forecast dispersion for our six indicators, normalized by the standard deviation (across time) of the respective median forecast. Across indicators, there is notable heterogeneity in average dispersion. There is also considerable movement in dispersion over time, as the blue solid line in Panel (b) shows. Specifically, we plot the three-month moving average of monthly average dispersion across all indicators. It is also evident that dispersion is correlated with our baseline uncertainty measure; but the correlation is far from perfect (Pearson correlation coefficient of 0.504 for the monthly averages).

\footnotetext{
${ }^{4}$ We check the robustness of our results to the choice of the uncertainty proxy in Section 5.
} 


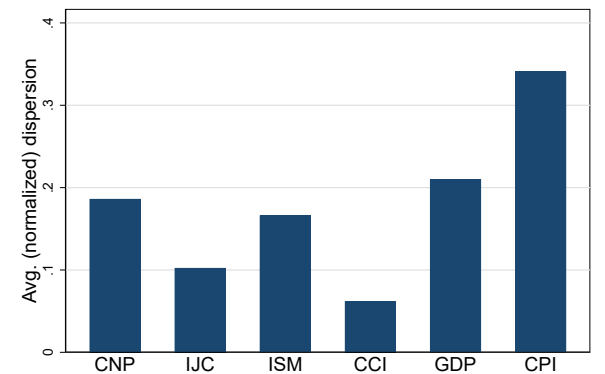

(a) Average dispersion

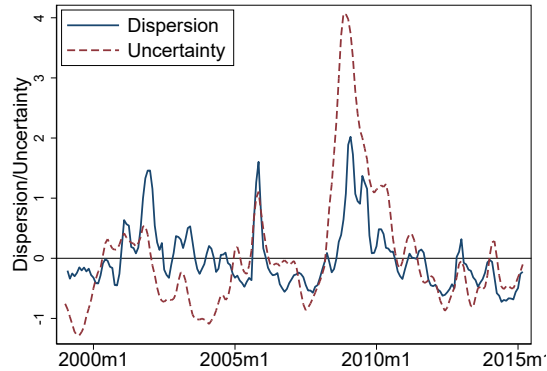

(b) Dispersion vs. uncertainty

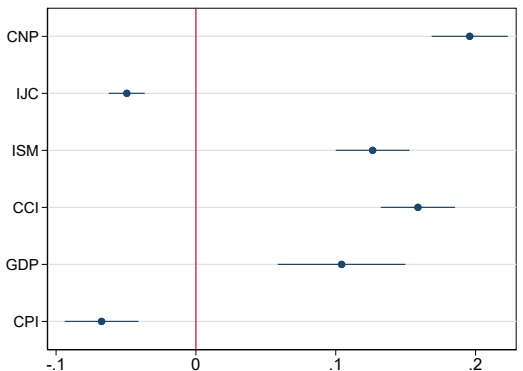

(c) Unconditional news effect

Figure 2: Panel (a): average forecast dispersion across indicators; panel (b): dispersion (solid blue line) vs. uncertainty (dashed red line); panel (c): unconditional effects of news on stock returns. Notes: dispersion in panel (a) normalized by the standard deviation (across time) of corresponding median forecasts.

\subsection{Empirical model}

We employ an event-study framework in which one event represents a point in time at which-potentially multiple -indicators are released. The dependent variable is the (percentage) change in futures prices between five minutes before the data release and five min-

utes afterwards, which we denote by $R_{t}^{ \pm 5}$. We regress these returns on the news variables, the forecast dispersion, $D_{t}^{i}$, the uncertainty measure, $U N C_{t}$, interaction terms between news and dispersion and news and uncertainty, respectively, and a set of control variables. Thus, our baseline regression, which we estimate by OLS, is given by

$$
\begin{aligned}
R_{t}^{ \pm 5}= & \alpha+\sum_{i=1}^{I}\left(\beta_{1}^{i} N e w s_{t}^{i}+\beta_{2}^{i} D_{t}^{i}+\beta_{3}^{i} N e w s_{t}^{i} \times D_{t}^{i}\right) \\
& +\beta_{4} U N C_{t}+\sum_{i=1}^{I}\left(\beta_{5}^{i} N e w s_{t}^{i} \times U N C_{t}\right)+\gamma^{\prime} X_{t}+\varepsilon_{t}
\end{aligned}
$$

where $\alpha$ is a constant, $I$ is the number of indicators (six in our case), $X_{t}$ is a vector of control variables with a corresponding vector of regression coefficients $\gamma$, and $\varepsilon_{t}$ is a zero mean i.i.d. error term. Note that we run this regression for all indicators jointly. The setup hence follows Beechey and Wright (2009) in that it allows for the possibility of parallel indicator releases at time $t$. Those right-hand-side variables belonging to indicators not released at the same time are set to zero. 
In our baseline, $U N C_{t}$ is a monthly measure of aggregate uncertainty in the real economy. In robustness checks, we also consider more granular measures that give us the aggregate uncertainty at the specific day before the event. Finally, $X_{t}$ includes the number of forecasters who submitted a forecast before a data release (to control for potential systematic dropout behavior) and dummies for the months February to December (to control for potential seasonality).

Given the estimates for the parameters $\beta_{1}^{i}, \beta_{3}^{i}$, and $\beta_{5}^{i}$, we can then analyze how strong the immediate news effect on future returns is for different levels of dispersion and uncertainty. Below, we present results that we compute by fixing the respective other variables at their sample means.

\section{Results}

While we are ultimately interested in the interaction effects between news and dispersion on the one hand and news and uncertainty on the other hand, we focus for a moment on the unconditional - without controlling for levels of dispersion or uncertainty - effects of our macroeconomic news variable on stock returns. Panel (c) of Figure 2 shows that these generally have the expected signs. For EMP, ISM, CCI, and GDP, a positive forecast error constitutes good news and the stock market reacts with a significant increase. For IJC and CPI on the other hand, the stock market takes a positive forecast error as bad news (e.g., because of looming interest-rate hikes or production capacity constraints in the case of CPI) and falls significantly.

Since we normalize macroeconomic news, the coefficients should be interpreted as the effect of an increase of news by one standard deviation. Take, e.g., the standard deviation of the news measure for GDP, which is 0.76 percentage points. The estimated coefficient implies

that futures prices increase by 0.104 percent, on average, when forecasters underestimate a release of GDP growth by 0.76 percentage points. 

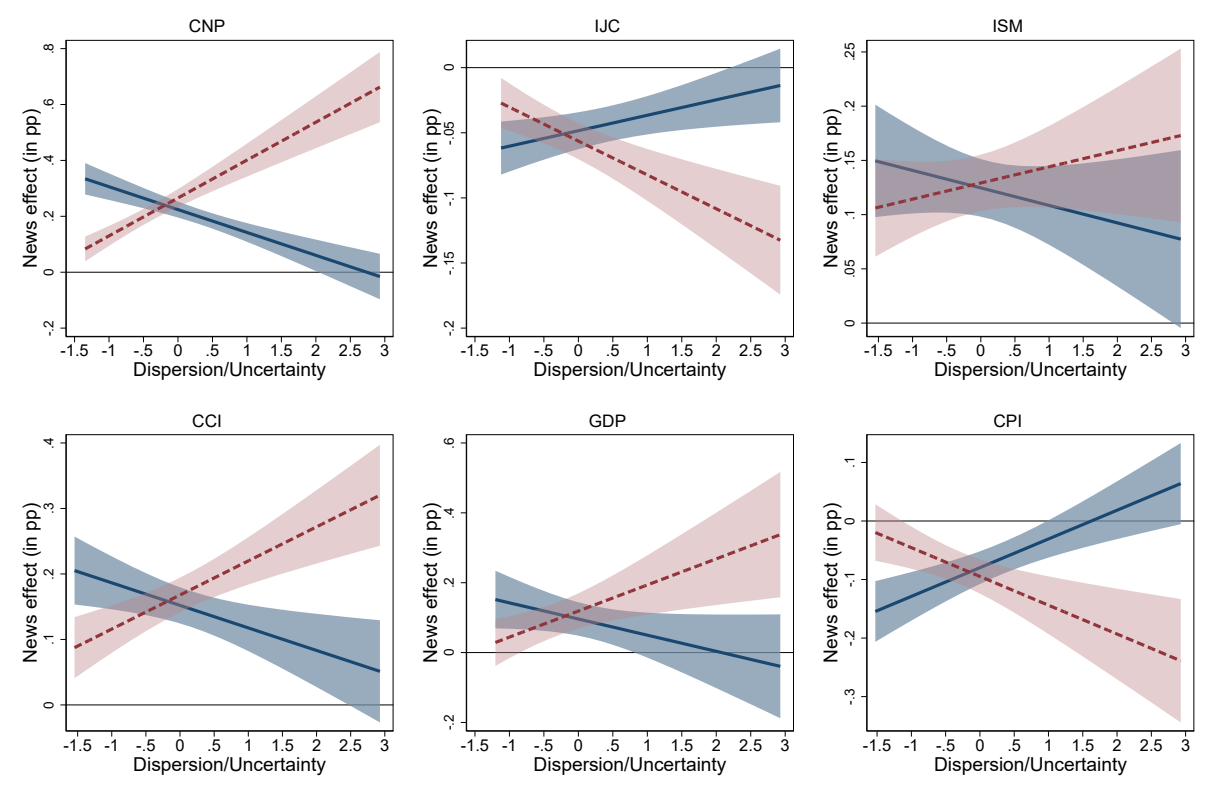

Varying Dispersion

Varying Uncertainty

Figure 3: Effects of news on stock returns for varying levels of dispersion and uncertainty. Notes: y-axis depicts marginal effects of news in p.p. for different levels of dispersion (blue solid line) and uncertainty (red dashed line); x-axis: "0" means dispersion/uncertainty is at its average level, "- 1 " ("1") indicates that it is one standard deviation below (above) its average level; shaded areas: 90\%-confidence intervals. All other variables are fixed at their sample means. For additional information, see Footnote 5.

Figure 3 then shows the main empirical result of the paper based on Regression (7). Specifically, we plot for each of the six indicators the marginal effects of news on S\&P 500futures returns for different levels of dispersion (blue solid line) and uncertainty (red dashed line). Here, dispersion and uncertainty both increase along the horizontal axis from left to right, while the vertical axis displays the marginal effects. ${ }^{5}$ The shaded areas are the 90\%-confidence intervals for the marginal news effects.

Remember that our model predicts that in times of high forecast dispersion, the market should react less to new information than in times of low dispersion. At the same time,

\footnotetext{
${ }^{5}$ Note that the $\mathrm{x}$-axis range is asymmetric because in the data dispersion (and uncertainty) exhibits large positive spikes and is therefore not symmetrically distributed. Note also that the effect sizes are normalized to make them comparable across indicators and uncertainty measures in the robustness checks. In particular, we standardize news and dispersion for each indicator and all uncertainty measures by subtracting the sample mean and dividing by the sample standard deviation.
} 
Table 1: Test of difference of slopes

\begin{tabular}{cccccccc}
\hline & CNP & IJC & ISM & CCI & GDP & CPI \\
\hline & \multicolumn{6}{c}{ Baseline } \\
Real uncertainty & 44.06 & 10.38 & 1.85 & 14.43 & 4.68 & 9.93 \\
& $(0.00)$ & $(0.00)$ & $(0.17)$ & $(0.00)$ & $(0.03)$ & $(0.00)$ \\
\hline \multirow{5}{*}{ Economic policy uncertainty } & 19.44 & 5.44 & 18.64 & 7.40 & 2.35 & 8.93 \\
& $(0.00)$ & $(0.02)$ & $(0.00)$ & $(0.01)$ & $(0.13)$ & $(0.00)$ \\
Implied volatility - VIX & 19.10 & 10.16 & 8.92 & 16.64 & 0.43 & 6.04 \\
& $(0.00)$ & $(0.00)$ & $(0.00)$ & $(0.00)$ & $(0.51)$ & $(0.01)$ \\
Monetary policy uncertainty & 0.03 & 3.03 & 7.89 & 1.70 & 1.17 & 0.25 \\
& $(0.85)$ & $(0.08)$ & $(0.00)$ & $(0.19)$ & $(0.28)$ & $(0.62)$ \\
\hline
\end{tabular}

Notes: Test of difference in slopes for the interaction effects between news and dispersion and news and uncertainty. Test statistic with p-value in parentheses. Economic policy uncertainty: daily newspaper-based proxy (Baker et al., 2016); monetary policy uncertainty: monthly newspaper-based proxy (Husted et al., 2020).

in times of higher uncertainty, the reaction to news should be stronger. Focusing first on dispersion and holding uncertainty at its average level, we see that in all six panels the slope of the solid blue line is sloping towards the horizontal zero line with increasing dispersion. That is - in line with our theoretic model - news have a smaller effect on stock markets if forecasts about the indicator of interest were more dispersed beforehand. The effect can be sizable. If the dispersion of forecasts for, e.g., non-farm payrolls is one standard deviation above its mean, the effect of a one-standard-deviation surprise is halved.

Importantly, the picture flips when we look at uncertainty. For all indicators considered, the dashed red line diverges from the horizontal zero line for higher levels of uncertainty, meaning that - again in line with the model - the stock market reaction is stronger if the macroeconomic news materializes in times of high uncertainty. Table 1, upper baseline panel, provides test statistics and p-values for tests of equality of the slopes of the interaction effects plotted in Figure 3. For five of the six indicators, the null of equality is rejected (ISM being 
the exception due to high estimation uncertainty), providing further evidence that forecast dispersion and uncertainty have very different effects on the market reaction to news.

\section{Robustness}

Given that measuring aggregate uncertainty is inherently difficult, we check the robustness of our results by considering a number of alternative proxies. The first two columns of Figure 4 show results equivalent to Figure 3 but with the economic policy uncertainty (EPU) measure of Baker et al. (2016) and the VIX, respectively, as the uncertainty proxy. These two proxies use very different approaches to measuring uncertainty. At its heart, EPU is based on the count of news articles that refer to the terms "economy, uncertainty and policy", while the VIX summarizes expected stock market volatility implied by options prices. In addition, both measures are available at daily frequency, which allows us to check whether using a monthly measure in the baseline is driving our results. ${ }^{6}$ Overall, results look very similar, which is also underscored by the respective rows in Table $1 .{ }^{7}$

\footnotetext{
${ }^{6}$ With the daily uncertainty proxies, we use the previous day's level of uncertainty in Regression (7).

${ }^{7}$ The difference in slopes becomes insignificant for GDP-growth news. However, it is important to keep in mind that GDP numbers are only released at quarterly frequency and we, therefore, have considerably fewer events compared to the monthly or weekly releases of other indicators.
} 
Economic Policy Uncertainty
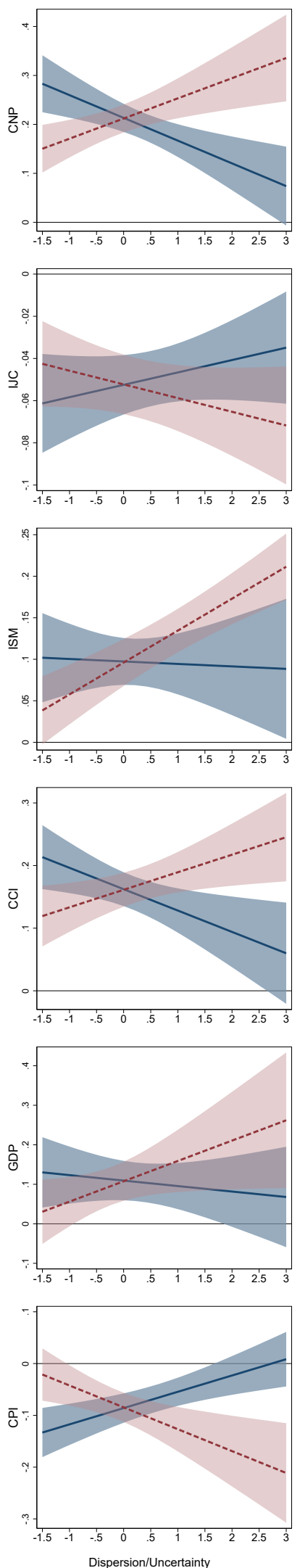

VIX
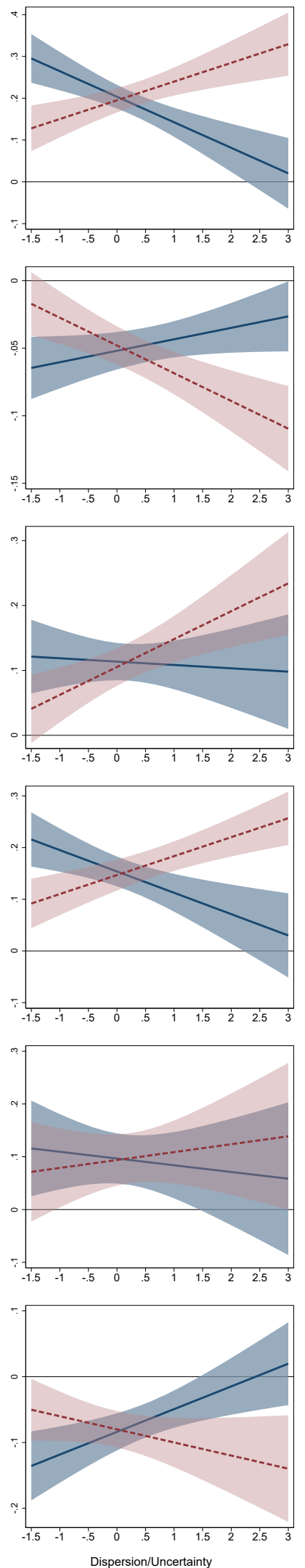

Monetary Policy Uncertainty
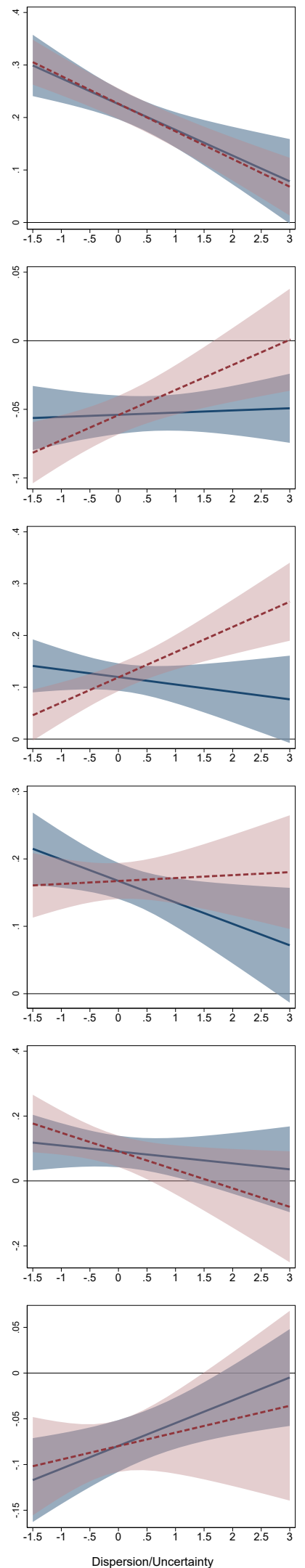

Figure 4: Robustness checks varying the uncertainty proxy. For notes, see Figure 3. 
On the other hand, looking at only monetary policy uncertainty (right column) - as measured by Husted et al. (2020) — yields a rather different picture. In line with the findings of Kurov and Stan (2018), higher monetary policy uncertainty actually weakens the stock market response to macroeconomic news. This is sensible if one considers that this measure explicitly measures uncertainty about the future interest rate. In times of monetary policy uncertainty, favorable news about the state of the economy raises the odds of an interest-rate increase. This leads to a stronger discounting of expected future dividends, counteracting the positive effects of the surprise. The effect is particularly strong for indicators that are deemed to be important for monetary policy decisions, see IJC and GDP, while ISM and CCI are less relevant in this context. Note, however, that the dampening effect of monetary policy uncertainty does not stand in contrast to our findings about the role of uncertainty and dispersion. Specifically, monetary policy uncertainty is only loosely connected to the concept of uncertainty about the fundamental as specified in our theoretical model of Section 2. It, therefore, might have a different but unrelated influence on the stock-market response to news.

In Figure A.1 in the appendix, we report results for additional uncertainty proxies. Using the macroeconomic uncertainty proxy of Jurado et al. (2015) or the financial uncertainty proxy of Ludvigson et al. (2021) does not change the overall picture. Both are very similar in construction to our baseline real uncertainty measure but cover somewhat different aspects of economic uncertainty - the financial uncertainty proxy focuses on a large set of financial time series while the macroeconomic uncertainty proxy covers both economic as well as financial time series. Finally, we also check that our results are not driven by the business cycle and control for recessions in our Regression (7); results are robust. 


\section{Conclusion}

One of the most important questions in asset pricing is how market prices react to news. We have shown both theoretically as well as empirically that the link between macroeconomic news and stock markets is affected by both uncertainty and expectation dispersion, but in opposite directions. We rationalize this finding by linking expectation dispersion to the (perceived) information content of news, and uncertainty to the economic value of this information. As both variables are changing over time, also the implied strength of the market reaction to news is time varying.

This insight has more general implications. For example, it speaks against tying policy reactions, such as monetary policy actions, to the development of certain indicators, like those pertaining to labor-market developments. Instead, the implication of macroeconomic news for the estimate of the current economic fundamentals has to be evaluated in the light of additional information. One important variable in this regard is expectation dispersion. Furthermore, our results underline that, depending on the context, expectation dispersion and uncertainty can be very different objects, although they are often used interchangeably. 


\section{References}

Andersen, Torben G., Tim Bollerslev, Francis X. Diebold, and Clara Vega (2007). "Realtime price discovery in global stock, bond and foreign exchange markets". Journal of International Economics 73 (2), 251-277.

Baker, Scott R., Nicholas Bloom, and Steven J. Davis (2016). "Measuring economic policy uncertainty". Quarterly Journal of Economics 131 (4), 1593-1636.

Beechey, Meredith J. and Jonathan H. Wright (2009). "The high-frequency impact of news on long-term yields and forward rates: is it real?" Journal of Monetary Economics 56 (4), 535-544.

Boyd, John H., Jian Hu, and Ravi Jagannathan (2005). "The stock market's reaction to unemployment news: why bad news is usually good for stocks". The Journal of Finance $60(2), 649-672$.

Ehrmann, Michael and David Sondermann (2012). "The News Content of Macroeconomic Announcements: What if Central Bank Communication Becomes Stale?" International Journal of Central Banking 8 (3), 1-53.

Fleming, Michael J. and Eli M. Remolona (1999). "Price formation and liquidity in the u.s. treasury market: the response to public information". Journal of Finance 54 (5), 19011915.

Gilbert, Thomas (2011). "Information aggregation around macroeconomic announcements: revisions matter". Journal of Financial Economics 101 (1), 114-131.

Gilbert, Thomas, Chiara Scotti, Georg Strasser, and Clara Vega (2017). "Is the intrinsic value of a macroeconomic news announcement related to its asset price impact?" Journal of Monetary Economics 92, 78-95.

Giordani, Paolo and Paul Söderlind (2003). "Inflation forecast uncertainty". European Economic Review 47 (6), 1037-1059.

Husted, Lucas, John Rogers, and Bo Sun (2020). "Monetary policy uncertainty" . Journal of Monetary Economics 115, 20-36. 
Jurado, Kyle, Sydney C. Ludvigson, and Serena Ng (2015). "Measuring uncertainty". American Economic Review 105 (3), 1177-1216.

Kurov, Alexander and Raluca Stan (2018). "Monetary policy uncertainty and the market reaction to macroeconomic news". Journal of Banking \& Finance 86, 127-142.

Lahiri, Kajal and Xuguang Sheng (2010). "Measuring forecast uncertainty by disagreement: The missing link". Journal of Applied Econometrics 25 (4), 514-538.

Law, Tzuo-Hann, Dongho Song, and Amir Yaron (2020). "Fearing the Fed: how Wall Street reads Main Street". Mimeo. Wharton School.

Ludvigson, Sydney C., Sai Ma, and Serena Ng (2021). "Uncertainty and business cycles: exogenous impulse or endogenous response?" American Economic Journal: Macroeconomics forthcoming.

McQueen, Grant and V. Vance Roley (1993). "Stock prices, news, and business conditions". Review of Financial Studies 6 (3), 683-707.

Yellen, Janet L. (2014). "Labor market dynamics and monetary policy". Speech at the Federal Reserve Bank of Kansas City Economic Symposium, Jackson Hole, Wyoming.

Zarnowitz, Victor and Louis A. Lambros (1987). "Consensus and uncertainty in economic prediction". Journal of Political Economy 95 (3), 591-621. 


\section{A Appendix}

Table A.1: Information on forecast data

\begin{tabular}{lccccc}
\hline Indicator & Acronym & Freq. & First obs. & \# obs & $\begin{array}{c}\text { Avg. \# } \\
\text { forecasters }\end{array}$ \\
\hline Chg. in non-farm payrolls & CNP & $\mathrm{m}$ & $01 / 08 / 1997$ & 197 & 70.5 \\
Initial jobless claims & IJC & $\mathrm{w}$ & $11 / 02 / 1999$ & 824 & 36.9 \\
ISM manufacturing index & ISM & $\mathrm{m}$ & $01 / 06 / 1998$ & 195 & 64.6 \\
Conf. Board cons. confidence & CCI & $\mathrm{m}$ & $23 / 02 / 1999$ & 193 & 59.4 \\
GDP growth & GDP & $\mathrm{q}$ & $30 / 04 / 1998$ & 66 & 68.3 \\
CPI inflation & CPI & $\mathrm{m}$ & $16 / 06 / 1998$ & 196 & 66.5 \\
\hline
\end{tabular}

Notes: Observed frequencies in our sample are weekly (w), monthly (m), and quarterly (q). The last observations in our sample are from March 2015. 

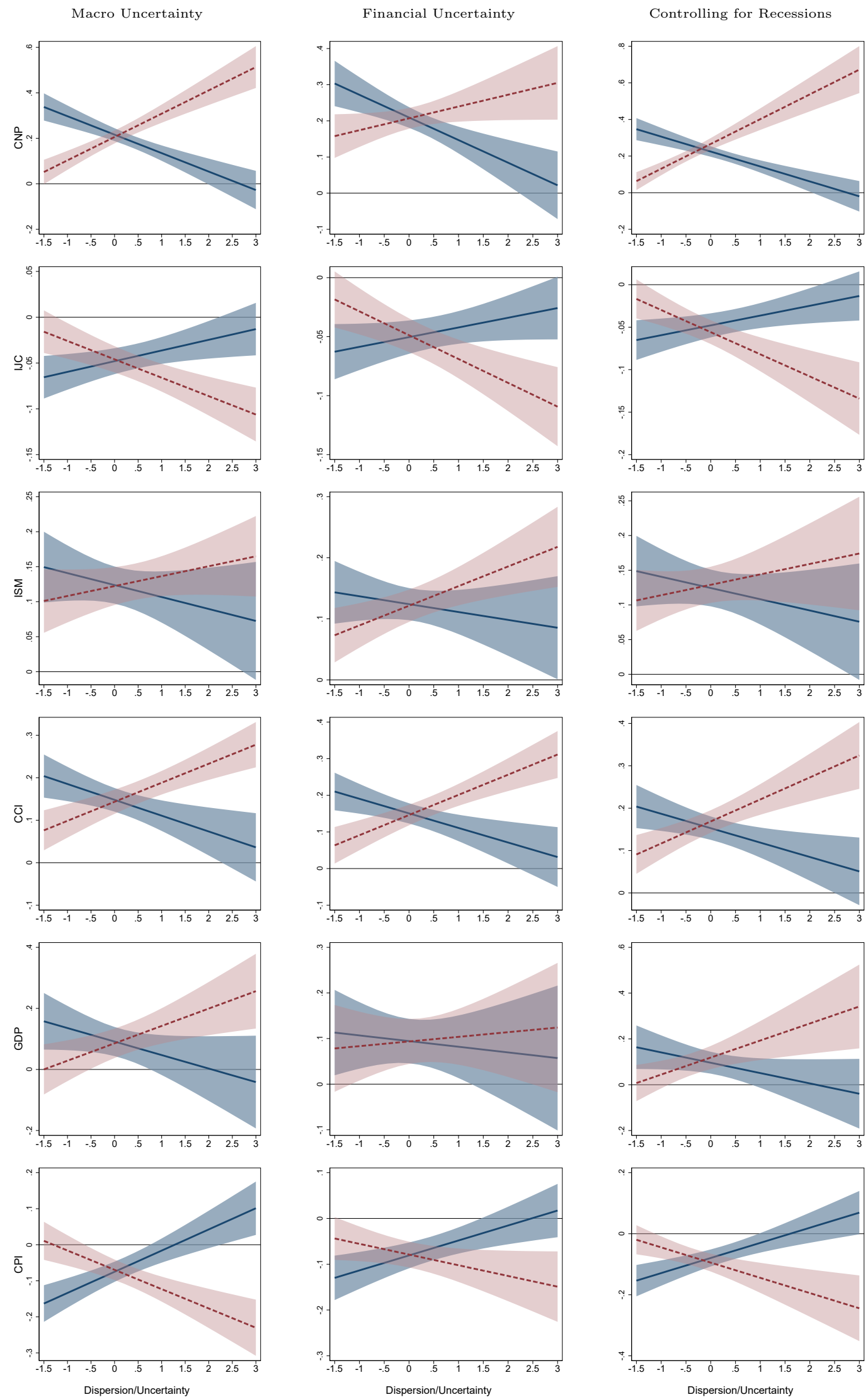

Figure A.1: Additional robustness checks. For notes, see Figure 3. 